\title{
The Revolution of Communication Media and Its Impact on Education
}

\author{
Lei He${ }^{1}$, Jian $\mathrm{He}^{2}$ \\ ${ }^{1}$ Research Institute of Education and Psychology of Southwest Ethnic Groups, Southwest University, Chongqing, \\ China \\ ${ }^{2}$ College of Computer Science and Communication Engineering, Guangxi University of Science and Technology, \\ Liuzhou, China \\ Email: tsg2@163.com, hechejian@163.com
}

Received 28 July 2015; accepted 18 August 2015; published 21 August 2015

Copyright (C) 2015 by authors and Scientific Research Publishing Inc.

This work is licensed under the Creative Commons Attribution International License (CC BY).

http://creativecommons.org/licenses/by/4.0/

(c) () Open Access

\begin{abstract}
Medium means "middle" originally. When it is used as an academic term in communication theory, it would be a bridge of information exchange between two agents. The more advanced medium is, the richer amount of information it can carry. And then the communicating way changes. The way of thinking changes, too. This paper firstly analyzed the development of communication process and the corresponding changes in media, and then discussed the major impact on education reform in different media. Each of the change will affect the media choice of teaching strategies and teaching effectiveness. Especially when the information media are used in education, much more information changing happens than ever before. People can learn with auditory, vision, tactus, olfaction, and so on. "Communication" became one of the most important keywords in the study supported by information technology.
\end{abstract}

\section{Keywords}

Communication Media, Revolution of Media, Education, Influence

\section{Introduction}

The word "communication" in English is derived from Latin commūnicāre, means "to share". There are so many different definitions of communication. It is defined by Wikipedia as the activity of conveying meaning through a shared system of signs and semiotic rules. And it is defined by Oxford English Dictionary that "Communication means to told or exchange of ideas and knowledge through language, text and images" [1]. Wilbur Schramm said that "Communication is a sign of a series of messages contain orientation to share" [2]. 
According to Educational Dictionary edited by Mr. Ming-Yuan Gu, communication is a kind of information exchange activities between people in order to share information, create common consciousness and the relationship between the coordinated action [3]. Beyond that, Pei-ren Shao defined communication as a kind of information activities through symbols, signal transmission, acceptance and feedback [4]. The communicating process includes three major elements. They are senders, receivers and media. Media can be defined as the material entity between the senders and receivers, used to load, expanding, extension, convey information symbols.

People's understanding of the media is very different at different periods, and with the development of information technology, the connotation of the medium is quietly changing. In ancient times, relatively backward productivity, the definition of media usually stays in the use of existing content level. For example, the medium was relations between people or things, which appeared in "The Old history of the Tang Dynasty of China" firstly. In English, the word "media", which is a plural form of "medium", appeared in the late 19th century or early 20th century, when was during the second industrial revolution. And because of the rapid progress of science and technology, various kinds of technology related to electricity emerge in large numbers. So "media" is refers to the medium or tools which could make things happen during that time. And the electronic media contain Slide projectors, movies, radios, televisions, and so on.

In the 1960s, the influence of information technology to people loomed. Marshall McLuhan, the Grand master of mass communication theory, thought the medium is everything, and everything is the medium. That's to say that all media can be related with the human body (the medium is the extension of human body). The root cause of this change is that with the innovation of science and technology, the spread of the media is in constant change.

\section{The Revolutionary of Communication Media}

Human's communication activities originated in the need of social production and social life. There have been the communication activities since the human society began. Man's earliest communication was in gestures and languages. That was a kind of direct transmission. With the enlargement of the scope of human activities, the simple way of direct transmission can no longer meet the needs of human's life. Then indirect transmission which need the aid of other medium appeared. With the constant improvement of the socialization of human, mode of communication has experienced several important stages of development from then on, and there has been a fundamental revolutionary on media. This revolutionary is basically the process of socialization as the main line. Each appeared a kind of new media, the information communication process can have a qualitative leap, delivering content will also enrich and develop.

As shown in Table 1, oral communications are the most primitive form of communication. Since humans have language, oral communication becomes the most important form of communication in human life. As human activity scope expanding gradually and socialization gradually improve, however, simple oral communication is no longer adapt to the spread of human communication needs. So the writing was invented.

From the initial knotting chronicle, to the invention of the oracle, and then to the bamboo slips, inscribed wooden slip, cotton silk, the use of the invention of paper-making technique, etc., human recorded the history of social development process in the form of text. They broke the limit of time and space for the first time in the human history, and provided valuable first-hand information for the information dissemination of the productivity development and the future of literature research. However, the scope of its influence is still very limited by handwriting only. The invention of printing made the spread of human civilization achievements to increase speed and breadth, fruits of human civilization can be spread far longer. A huge revolution happened in educational history.

Table 1. The change of human communication.

\begin{tabular}{|c|c|c|c|c|c|}
\hline PHASE & $\begin{array}{l}\text { Communicating } \\
\text { Directly }\end{array}$ & $\begin{array}{l}\text { Communicating } \\
\text { Directly }\end{array}$ & $\begin{array}{l}\text { Communicating } \\
\text { Directly and Indirectly }\end{array}$ & Communicating Indirectly & $\begin{array}{l}\text { Communicating Directly } \\
\text { and Indirectly by Media }\end{array}$ \\
\hline FORM & ORAL & ORAL & ORAL \& TEXT & $\begin{array}{c}\text { ORAL, TEXT, PHOTOGRAGH, } \\
\text { AUDIO,VIDEO }\end{array}$ & $\begin{array}{l}\text { AURAL, VISUAL, } \\
\text { HAPTIC,AND SO ON }\end{array}$ \\
\hline MEDIA & Medialess & $\begin{array}{l}\text { Physical media such } \\
\text { as stones, plants, etc. }\end{array}$ & $\begin{array}{l}\text { Print media such as books, } \\
\text { newspapers, magazines, etc. }\end{array}$ & $\begin{array}{l}\text { Electronic media such as slide } \\
\text { shows, movies, } \\
\text { radios, televisions, etc. }\end{array}$ & $\begin{array}{l}\text { Information media such as } \\
\text { computers, internet, } \\
\text { virtual reality, etc. }\end{array}$ \\
\hline
\end{tabular}


The second industrial revolution caused a wave of science at the end of the 19th century. With the invention of the camera and the phonograph, the slide show and movies become the new media. Radio and television is also emerge almost the same time. The communication of the human experienced a historic change again. Human is no longer limited to simply text reading now. There are unprecedented physical pictures, sounds and images in the communicating history of people. The communication of people become more rich and colorful up from then on.

The modern computer technology, communication technology, multimedia technology and network technology is to compose the new chapter in human communication. Now the amount of information carried by the new media is far from traditional media. The information should be much more diverse and multidimensional than ever before. People can even spread the tactile information by using virtual technology. As the Internet gradually into the life of people, time and distance no longer become the obstacle of communication. The human society really run into the era of "global village" [5].

In the communication history, as a result of media revolutionary, the way of human communication mainly experienced such a course which was from direct way to the indirect way. With the rapid development of information technology, the performance of the media is no longer a technical bottleneck in the process of communication. people can choose their communicating way according to their need more freely. Mode of communications, therefore, have the trend which is from directly to indirectly again. This is not a simple loop of historical process. But it is a spiral process that is in the support propagation process by information technology. We are going through the change of information medium phase.

\section{The Impact on Education}

Each revolution of medium change is accompanied by the progress of social productivity. And they all reflect the human's appeal which improved for more abundant information content and form of activity. Though the invention of the media is rarely dedicated to education field, and those new media can't always show their special education functions at the beginning of the media use, history has proved that almost every kind of new media revolution have brought far-reaching influence to education. Especially during the previous media revolutionary since the second industrial revolution, a fundamental change is happening in teaching content, teaching \& learning methods and other various aspects [6]-[8].

Before print media appeared for a long time, there was almost no big change in education. People learn from Seniority and Clansman by oral, realias, visual aids, or hand written books. As shown in Table 2, there were three big revolutions in the history of education after the printing appeared. First one happened after the appearance of print media. At that time, because of the rapid development of the industry, much more production skills were needed to be mastered by people. With the print media to be introduced into the educational process, more students were allowed to learn together. And then, the specialized teacher appeared. The second one happened during the second industrial revolution. Electronic media come out, and were widely used in education. More and more students could learn by electronic way, especially by slide shows and educational movies. During late World War II and after the end of WWII, audio-visual teaching was developed in the military and industrial training in the United States. With the electronic media, soldiers were trained to be the navy, the army and the air force, and ordinary young men and women were trained to be manufacture arms and ship technical workers in a very short period of time. This is one of the most successful cases of media using in education, which had been written into the textbooks of educational technology.

The third educational revolution happened in recent decades after the information technology development. We can use information media to individualized teaching, which contain no only individual instruction, but also

\begin{tabular}{cccccc}
\multicolumn{2}{l}{ Table 2. The change of education. } & & & & \\
\hline MEDIA & Medialess & Physical media & Print media & Electronic media & Information media \\
$\begin{array}{c}\text { INSTRUCTION } \\
\text { MODE }\end{array}$ & Individual Instruction & Individual Instruction & Small Class Teaching & $\begin{array}{c}\text { Audio-visual } \\
\text { Teaching }\end{array}$ & $\begin{array}{c}\text { Individualized } \\
\text { Teaching }\end{array}$ \\
$\begin{array}{c}\text { INFORMATION } \\
\text { SOURCE }\end{array}$ & Seniority, Clansman & Seniority, Clansman & Teachers (Sophists) & Teachers & $\begin{array}{c}\text { Teachers, Companions } \\
\text { \& Everybody }\end{array}$
\end{tabular}


group instruction, even any form we like. People can learn by auditory, vision, tactus, olfaction, and so on. "Communication" is one of the most important keywords in the study supported by information technology.

Beyond that, the influence on education by media change include at least the following three aspects:

\subsection{The Change of Communicating Content}

The capacity of digital information is big, and the speed of information update is much faster than the traditional information. That's the biggest difference between digital information and traditional analog information. There are vast, fresh information in front of communicators (teachers) and the receivers (students). However, the information authenticity and reliability has decreased without the experience of time. Thus, better access, use, identification and evaluation to information is needed to obtain valuable information.

\subsection{The Changes of Knowledge Acquiring Approach}

In traditional form, the approaches of learners to acquire knowledge was mainly from teachers. Because of the single source of the information, the knowledge learners can get is very limited. In the modern multimedia, networked and more diverse environment, the information which can be accessed by learners has become wider and wider. There are all kinds of information in the newspapers, magazines, movies, television and the Internet, no matter whether learners need or don't need, like or dislikes, even is suitable or not suitable for learners, which can be chosen by learners according to their own needs, interests and any suitable for their own resources to learn. Sometimes, the learners have more rich information sources than teachers. Teachers are no longer the only source of students to acquire knowledge.

\subsection{The Change of the Communicating Way}

One of the most important revolution of the medium is the change of its interactive function. One-way communication media has changed to two-way or multidirectional communication medium. In this context, educators are no longer merely imparter of knowledge, and no longer teaching process controller or authority. Learners are no longer just the passive recipients of knowledge, too. They became the active selectors of knowledge in the communication process. The position between the teachers and students has fundamentally changed. They are more equal each other.

\section{Conclusion}

Medium means "middle" originally. When it is used as an academic term in communication theory, it would be a bridge of information exchange between two agents. The more advanced medium is, the richer amount of information it can carry. And then the communicating way changes. The way of thinking changes, too. The transformation of the media will inevitably affect the effect of education, especially the efficiency of teaching. Medium revolutionary will also affect the teaching strategies in the process of selection. Multiple, networked media can provide advanced teaching platform and rich teaching resources for the teaching. It can provide the technical support for learners and teachers to adopt more initiative learning style and teaching strategy. Educators will be more conducive to advanced education concept applied to teaching practice. It greatly promotes the development of the education reform, too.

\section{Acknowledgements}

This study is supported by The New Century Educational Reform Project in GuangXi in 2013 “Teaching Reform Exploration and Practice about the Professional Practice Curriculum Project of Digital Media Technology” (Grant No.: 2013JGA194) and Scientific Research Project of Guangxi Universities in 2014 "Decomposition and Reconstruction of Culture Transmission Field in Information Age”(Grant No.: LX2014201).

\section{References}

[1] Nan, G.N. and Li, Y.L. (2005) Science of Educational Communication. 2nd Edition, Higher Education Press, Beijing.

[2] Schramm, W. (1969) Mass Communication. University of Illinois Press.

[3] Gu, M.Y. (1986) Educational Dictionary. Shanghai Educational Publishing House, Shanghai. 
[4] Shao, P.R. (2000) Communication Science. Higher Education Press, Beijing.

[5] Bu, W. (1996) Enter the “Global Village”, Mass Communication and the Development of China's Children. Sichuan Children's Publishing House, Chengdu.

[6] Liu, M.F. (2004) Parsing the Three Historic Clues of Development of Educational Technology in the USA. Compared Education Review, 8, 33-37.

[7] Zheng, X.D. and Chen, W.Z. (2012) The Significance of Historical Studies in Instructional Technology: From the View on Communication studies as Theoretical Foundation of the Field. Modern Distance Education Research, 4, 914.

[8] Zhu, J. and Cai, J.D. (2009) Automatic Education: Historical Education on Early Educational Technology of China and America. Modem Educational Technology, 10, 21-23. 